\title{
Crescimento diferencial è nutriçào em Catoprion mento (Characoidei). Peixe lepidófago da Amazônia.
}

\author{
Ivanzir Vieira (*) \\ Jacques Géry $(*)$
}

\begin{abstract}
Resumo
Catoprion mento (Caracoldei) é um serrasalmídeo lepidófago que se alimenta principalmente de insetos, quando jovem; com 75 a $125 \mathrm{~mm}$ de comprimento padrão consome insetos e escamas em igual porcentagem, tendo uma distinta preferência por escamas, quando adulto. O cresciments do trato digestivo, altura do corpo e largura da cabeça (representada pelo espaço interorbital) mostra forte alometria positiva, com um ponto crítico de crescimento para a altura. A cabeça mostra alometria negativa em seu crescimento. O diferencial e a preferência alimentar eståo provavelmente relacionados.
\end{abstract}

\section{INTRODUÇÃO}

No decorrer da pesquisa realizada na Usina Hidrelétrica de Curuá-Una visando o estudo das condições limnológicas daquela represa, atendendo ao convênio entre o Instituto Nacional de Pesquisas da Amazônia e a Eletrobrás, tivemos a oportunidade de coletar exemplares de Catoprion mento (Cuvier), Serrasalmidae guianense-brasileiro, cuja preferência alimentar pelas escamas de outros peixes é conhecida. Uma vez que a amostragem possibilitava, resolveu-se realizar o estudo de seus hábitos alimentares e crescimento contribuindo para o melhor conhecimento da biologia da espécie.

Em 1859, Kner encontrou muitas escamas no estômago de um espécime com cerca de $150 \mathrm{~mm}$ de comprimento. Porém, situou $C$. mento como sendo predador. Gosline (1951), ao examinar quatro espécimes, encontrou dois com escamas no estômago e aparentemente estava consciente do significado de sua presença. Ladiges (com. pessoal) observou em aquário o comportamento do peixe, o qual arranca fileiras verticais de escamas de baixo para cima, graças à sua proeminente mandíbula, que contém dentes mais ou menos evertidos.
Géry $(1969,1972)$ e Roberts (1970) comentaram a respeito do hábito de comer escamas desses peixes. Contudo, apesar dos trabalhos acima mencionados, nenhum estudo pode ser feito sobre crescimento relativo ou sobre peculiaridades de sua dieta devido à relativa escassez de material disponível nos museus. Um de nós (I. V.) foi suficientemente afortunado para assegurar boa amostragem de $C$. mento com diferentes tamanhos, possibilitando-nos 0 estudo desses aspectos.

\section{MATERIAL E MÉTODOS}

Foram estudados 40 exemplares de $C$. mento, provenientes do rio Curuá-Una e seus tributários. As coletas foram feitas acima, dentro e abaixo da Usina Hidrelétrica de CuruáUna, a 70 quilômetros de Santarém, no Estado do Pará. O período de capturas foi de julho de 1977 a maio de 1978. O comprimento padrão do material estudado variou entre $47,5 \mathrm{e}$ $156 \mathrm{~mm}$. Todas as medidas de comprimento mencionadas no texto se referem ao comprimento padräo ( $=$ "Standard Lenght") .

As seguintes medidas foram tomadas: comprimento (40 exemplares), altura (40 exemplares), cabeça (40 ex.), interorbital (40 ex.) e mandíbula (40 ex.). Na contagem dos raios ramificados utilizou-se: dorsal ( 39 ex.) e anal (39 ex.). Os espinhos da serra ventral foram contados com utilização de lupa. O estômago (37 exemplares examinados) foi exposto mediante dissecação dos peixes e seu conteúdo, depositado em placa de Petri, examinado sob lupa. As medidas do comprimento do intestino (37 exemplares examinados) săo aproximadas devido às dificuldades naturais de realizá-las com precisão. Os dentes foram examinados sob iupa.

(') - Universidade Federal de Juiz de Fora, Minas Gerais.

(*) - Centre National de la Recherche Sclentifique, France. 
Os resultados das medidas da altura corporal (à frente da nadadeira dorsal), comprimento da cabeça (sem membrana), distância interorbital e comprimento da mandíbula foram transformados em logarítmos decimais objetivando uma melhor apreciação das alometrias. As regressões foram calculadas utilizando-se o método ordinário dos mínimos quadrados e tomando-se o comprimento padrão como variável independente (abscissa).

\section{DESCRIÇÃO COMPLEMENTAR}

Altura do corpo 1,50 (adultos) a 1,85 (jovens, vide alometria) no comprimento; cabeça 3,25 (jovens) a 3,60 (adultos, vide alometria) no comprimento; interorbital 2,45 (adultos) a 3,35 (jovens, vide alometria) no comprimento da cabeça; mandíbula 2,15 a 2,45 no comprimento da cabeça; dorsal 13-15 raios, com a seguinte distribuição: 13, 2 exemplares; 14,27 exemplares; 15,10 exemplares.

Anal 31-36, com a seguinte distribuiçäo: 31, 1 exemplar; 32, 3 exemplares; 33, 10 exemplares; 34,13 exemplares; 35,9 exemplares; 36,3 exemplares. Serra $30-38$, geralmente 31-36, o último espinho (par) em frente ao ânus, nenhum ocorrendo após este. Escamas 40-44/78-90/30-33.

O filamento dorsal nos machos alcança a nadadeira caudal; nas fêmeas é mais curto, não atingindo a caudal.

\section{CRESCIMENTO DIFERENCIAL}

O crescimento da mandíbula, embora não demonstrado no presente trabalho, parece ser isométrico. As regressões de três outras dependentes variáveis (altura, cabeça e interorbital) constam da Fig. 1.

Registrou-se uma nítida alometria positiva para a altura, nos jovens; de 47,5 até $64,0 \mathrm{~mm}$ (10 exemplares) a altura do corpo cresce mais rapidamente que o comprimento (coeficiente de regressão $b=1,352$ ) nos 30 peixes restantes $(74,5$ a $156,0 \mathrm{~mm}$ de comprimento) observou-se pequena alometria positiva $(b=1,054)$. A Fig. 1 mostra com clareza um ponto de crescimento crítico quando o peixe atinge cerca de
$70,0 \mathrm{~mm}(\log 1,840)$. A diferença entre as duas inclinações $(1,352-1,054=0,298)$ foi analisacia pelo teste $t$, envolvendo variâncias de $x, y$ e xy. $O$ valor 3,75 (para $N_{1}+N_{2}-4=36$ g.l.) mostra que a probabilidade de que a diferença não ocơra devido ao acaso é maior que 0,999 .

O crescimento da cabeça mostra uma alometria negativa, como ocorre muitas vezes nos Serrasalmidae (vide Géry, 1972). Aqui, também, um ponto crítico semelhante pode ser constatado ( $75 \mathrm{~mm}$ de comprimento), mas as duas inclinações $(b=0,963$ para os 10 espécimes maiores e $b=0,908$ para os outros 30 ) não apresentam diferença significante.

O espaço interorbital mostra alometria positiva, mais forte para os 10 menores espécimes $(b=1,283)$, menor para os 30 restantes $(b=1,105)$. O ponto crítico, da mesma forma como foi registrado no parágrafo anterior, ocorra também a cerca de $75 \mathrm{~mm}$ de comprimento. A diferença entre as duas inclinações não é significante.

\section{ALIMENTAÇÃ̃o}

Dos estômagos examinados, 3 estavam vazios. O resultado nos restantes 34 foi: 15 contendo escamas de peixes, $10 \mathrm{com}$ insetos, 7 com escamas + insetos, 1 com escamas + insetos + ovos e $1 \mathrm{com}$ detritos vegetais (folhas).

As escamas pertenciam a peixes das familias Anostomidae, Hemiodidae, Curimatidae (?) e Cichlidae. Os insetos pertenciam a três grupos: Homoptera, Odonata (Libellulidae) e Diptera (Chironomidae).

Não foi observada mudança no número e forma dos dentes, no decorrer do crescimento dos peixes.

O estômago, particularmente grande, pode acomodar grande quantidade de escamas e representa 20 a $40 \%$ do comprimento total do trato digestivo. Este, por sua vez, está contido cerca de 0,75 a 1,35 no comprimento; sem o estômago esta relação altera-se para cerca de 1,05 a 2,2 . A despeito da falta de precisão na medida do intestino, encontrou-se uma correlaçãc de $r=0.92$ deste com $\alpha$ comprimento. 


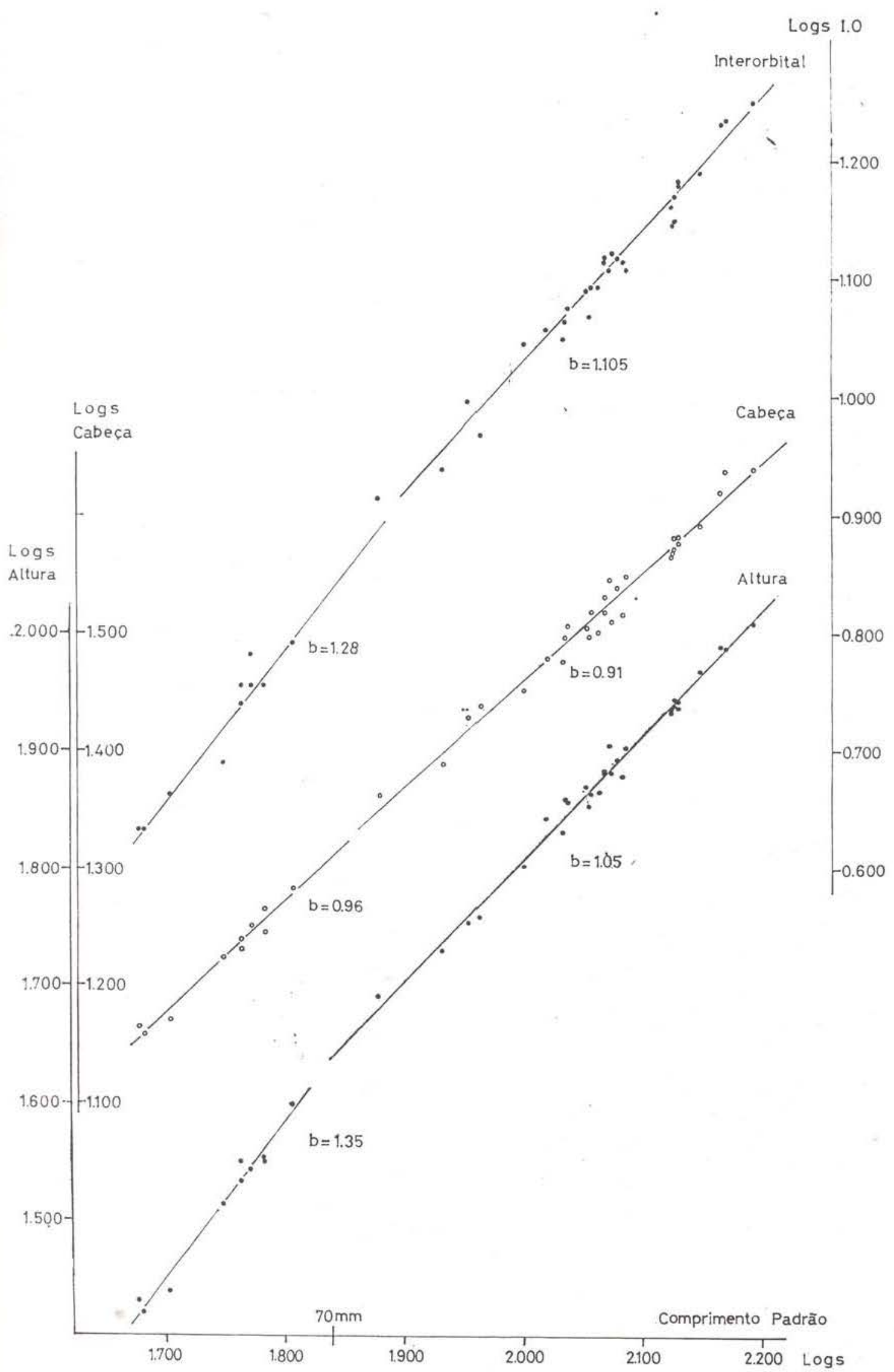

Fig. 1 - Regressōes da altura do corpo, comprimento da cabeça e distâncla interorbital sobre o comprimento padrão de Catoprion mento.

Crescimento... 
Ocorre forte alometria positiva (b 1,35 , com coordenadas logarítmicas), i. e., $\alpha$ crescimento do intestino é relativamente mais rápido que o do comprimento do peixe.

Existe, ainda, uma correlação entre o tamanho (idade) do peixe e suas preferências alimentares: pequenos peixes - até cerca de $70 \mathrm{~mm}$ - alimentam-se preferentemente de insetos (cerca de 66\%): peixes de tamanho médio ( 75 a $125 \mathrm{~mm}$ ) consomem a mesma proporção de insetos e escamas; peixes maiores, com 130 a $160 \mathrm{~mm}$, alimentam-se, preferentemente, de escamas. Somente um exemplar $(12 \%)$, dos que foram examinados, havia consumido somente insetos.

\section{CONCLUSÃo}

Catoprion mento não é um estrito "comedor de escamas", alimentando-se, também, de insetos e, ocasionalmente, de ovos e até foIhas. Existe, aparentemente, uma dieta preferencial conforme a idade do peixe. Essa preferência alimentar parece estar correlacionada com o crescimento diferencial do trato intestinal e, possivelmente, com o ponto crítico mencionado.

\section{AgRAdECIMENTOS}

Este trabalho contou com o auxílio dos estudantes do curso de Pós-Graduação em Biologia de Água Doce e Pesca Interior do Instituto Nacional de Pesquisa da Amazônia, Antonio F. Dias, Efrem J. G. Ferreira, J. Eduardo Forero, José C. O. Malta, Luiz P. Aragão, Manoel Pereira Fo., Mauro C. L. B. Ribeiro, Míriam L. Carvalho, Oséas M. Holanda, Ronaldo B. Barthlen, Sérgio Annibal e Vera M. F. Silva, além de Lúcia $H$. R. Py-Daniel, que estudaram o conteúdo estomacal dos exemplares utilizados no presente trabalho, e Vitor Py-Daniel, entomólogo, que identificou os artrópodos.

\section{SUMMARY}

The scale-eating Serrasalmid fish Catoprion mento (Characoidei) eats mostly insects when young, then about an equal percentage of insects and scales of other fishes at a medium size, and has a distinct preference for scales when adult. At the same time, the intestine tract, the body depth and the width of the head (as represented by the interorbital space) show a strong positive allometry, with a critical point of growth for the depth. The head length has a negative allometry. The differential growth phenomenons and the food preferenda are possible related.

\section{BIBLIOGRAFIA}

GÉRY, J.

1969 - The fresh-water fishes of South America. In: Biogeography and ecology in South America, ed. E. J. Fittkau et al. - Mo. nographiae biol., The Hague, 2 : 828-848.

1972 - Poissons characoides des Guyanes. I. Generalités. II. Famille des Serrasalmidae. - Zool. Verhand., Leiden, 122: 1-250, pls. 1-16.

GosLine, W. A.

1951 - Notes on the characid fishes of the subfamily Serrasalminae. Proc. Calif. Acad. Sci., (4) 27 (2) : 17-64, pls. 1-3.

KNER, R.

1859 - Zur Familie der Characinen, III. Folge der ichthyolosgischen Beiträge (I. Abt.). Denkschr. K. Akad. Wiss., Wien, 17: 137-182, pls. $1-9$

ROBERTS, T. R.

1970 - Scale-eating American characoid fishes, with special reference to Probolodus heterostomus. Proc. Calif. Acad. Sci , (4) 38 (20) (Festschrift for George Sprague Myers) : $383-390$.

(Aceito para publicaçăo em 08/03/79) 